\title{
E-commerce promotes trade in invasive turtles in China
}

\author{
Sha Liu, Chris Nemman, Christina D. Buesching, David W. Macdonald \\ Yu Zhang, Kai-Jie Zhang, Feng Li and Zhao-Min Zhou
}

\begin{abstract}
Freshwater habitats in China are potentially suitable for invasive alien turtle species and, consequently, raising turtles in aquaculture facilities and the trade in turtles this supplies pose risks to habitats and native wetland communities when exotic turtles escape or are released deliberately. Online trade (e-commerce) is making an increasing contribution to turtle sales in China, seemingly driving demand and thus potentially exacerbating the risk of release. We document the scale and spatial pattern of online sales of non-native turtles over 90 days on China's Taobao.com e-commerce site. The majority of sales were in the ecologically sensitive middle and lower Yangtze river basin $(82.35 \%$ of $>840,000$ slider turtles Trachemys scripta elegans, and $68.26 \%$ of $>100,000$ snapping turtles, Chelydridae spp.). These species are native to the Americas. Concurrently, over 2008-2018, we found 104 mentions of feral turtle issues listed on Baidu News where, among the 53 prefectures mentioned, issues with invasive turtle populations also focused predominantly in the middle and lower Yangtze river basin. Although circumstantial, this association suggests that the substantial online sale of alien turtles could be having detrimental effects in China's Yangtze river basin. It is important to safeguard these wetland habitats, which are of global importance, by improving policies for detecting and regulating invasive alien turtle issues and by warning consumers about the ecological hazard of their purchases.
\end{abstract}

Keywords Asia, biodiversity, Chelydra, China, Macrochelys, online trade, Trachemys, Yangtze river basin

ntroductions of invasive alien species have a major global
impact on ecosystem integrity (Macdonald et al., 2007;
Pejchar \& Mooney, 2009), with negative consequences for
community structure and diversity that can persist for dec-
ades (Sharpe et al., 2017). Developing countries undergoing
rapid economic growth can be especially vulnerable to such

Sha Liu, Yu Zhang, Kai-Jie Zhang, Feng Li and Zhao-Min Zhou (Corresponding author, (1) orcid.org/0000-0003-4824-7371) Key Laboratory of Southwest China Wildlife Resources Conservation (Ministry of Education), China West Normal University, Nanchong, China. E-mail zhouzm81@gmail.com

Chris Newman, Christina D. Buesching and David W. Macdonald Wildlife Conservation Research Unit, Department of Zoology, The Recanati-Kaplan Centre, University of Oxford, Oxford, UK

Received 22 February 2019. Revision requested 17 April 2019.

Accepted 16 August 2019. First published online 17 January 2020. introductions, driven by new commercial opportunities (Pelicice et al., 2014). In China the profitability of selling exotic species has led to substantial numbers being bred in captivity to supply demand for pets, Chinese traditional medicine, and food (Lin et al., 2015). Online trade, or e-commerce, has become a major distribution channel, exacerbating the spread of invasive species and challenging biosecurity (Lenda et al., 2014; Humair et al., 2015).

Although the slider turtle Trachemys scripta elegans (Ficetola et al., 2009) and snapping turtles of the genera Chelydra and Macrochelys (Kobayashi et al., 2006), all native to the Americas, are amongst the most invasive exotic species, the market for these taxa and the extent of their colonization has not been assessed in China. Turtles are bred in freshwater aquaculture facilities in China, $65 \%$ of which are in the Yangtze river basin (Chen et al., 2009). This region is highly susceptible to the establishment of alien invasive turtles (e.g. T. scripta elegans, Xiao, 2015; Chelydra serpentina, Chen et al., 2017; Macrochelys temminckii, Chen, 2017) because of the area's suitable climate and habitats. Here we evaluate how online trade (e-commerce) adds a new dimension to this problem, facilitating purchase of turtles, driving production in breeding facilities, and risking escape and release of turtles along all stages of the supply chain (Kraus, 2015). We document national online sales of live slider and snapping turtles via mainland China's largest domestic consumer-to-consumer internet trading platform, Taobao.com (a subsidiary of the Alibaba Group). We examine the spatial distribution of turtle sales to generate a sales map, and explore how this is associated with media reports of feral turtle populations in the Yangtze river basin, and provide recommendations for how to mitigate turtle trade and the establishment of invasive species.

We conducted three surveys (24 February-27 March 2017, 14 April-10 May 2017, 3-18 October 2017), searching for the terms 'slider turtle, live' and 'snapping turtle, live' (in Chinese) on Taobao.com. We included 'live' to distinguish animals traded, as opposed to toys, pet supplies, and similar items. To avoid recording a vendor's goods sold more than once, we re-inspected vendors after an interval of at least 30 days to see if they had made subsequent sales of additional goods. When new vendors comprised $<3 \%$ of total vendors on our list in each survey, we ceased searching for additional vendors, assuming we had accounted for the majority. 
Taobao.com provides retrospective transaction information, including 'species' (which we verified from the description and photographs provided by sellers), 'item location' (i.e. site of origin of the sale, used to calculate freight charges, and which we presumed to be accurate), and 'successful transactions', which provided the number of individual animals sold during the 30 days preceding our inspection of Taobao trading records (one transaction equates to one animal traded). The destination of sales was not, however, included and thus did not form part of our analyses. Data were collected and analysed using prefecture as the administrative unit (mainland China comprises 334 prefectures, in 34 provinces, and four province-level municipalities). To determine whether the number of sales (log-transformed) were similar between neighbouring prefectures, which would suggest trading hotspots, we used Moran's I (Moran, 1950) to assess spatial autocorrelation at 10 distance classes $(42-3,482 \mathrm{~km}$ for the slider turtle and 42-2,937 km for the snapping turtle) using Spatial Analysis in Macroecology 4.o (Rangel et al., 2010).

To examine for any link (whether causal or coincidental) between areas where sales originated and sites where invasive freshwater turtles were recorded, we searched Baidu News (on 8 August 2018) for reports containing the search term 'exotic, turtle' (in Chinese) in the full text of articles for 2008-2018. We tested whether the proportion of prefectures reporting invasive non-native turtles were significantly $(\mathrm{P}<0.05)$ higher in trading hotspots, using cross tabulation with a $\chi^{2}$ test. We applied Yates's correction for continuity because of the small number of news reports available.

From the three surveys, each covering 1 month (30 days) of trade (i.e. monitoring $25 \%$ of total annual commerce), we recorded 840,193 transactions involving slider turtles (by 469 vendors) and 108,047 involving snapping turtles (by 472 vendors), which extrapolates to naive estimates of annual trade volumes of c. 3,360,00o and 432,000, respectively. Geographical patterns of sales were similar between taxa, although sales originated in only 106 of 338 prefectures and province-level municipalities (slider turtles in 89, snapping turtles in 70; Fig. 1). From the spatial correlation coefficient at the first distance class $(\mathrm{P}<0.05)$ we found clustering for log-transformed regional sales of slider turtles (at distances of $42-339 \mathrm{~km}$, involving 782 pairs of prefectures, Moran's $I=0.12$ ) and snapping turtles (at distances of 42-304 km, involving 482 pairs of prefectures, Moran's $I=0.14)$. This revealed a sales hotspot, with $82.4 \%$ of slider turtles and $68.3 \%$ of snapping turtles sold from 26 and 17 prefectures, respectively. These prefectures lie in the middle and lower reaches of the Yangtze river basin, the predominant aquaculture region in China, from where turtles are bred and disseminated through wholesalers, retailers and consumer-to-consumer traders (Fig. 1). The majority of the sales of slider turtles originated from Shanghai $(198,289$ individuals), Suzhou $(174,698)$ and
Changsha $(165,952)$, and of snapping turtles from Suzhou $(53,572)$, Shanghai $(12,620)$ and Changsha $(3,806)$.

We found 30 news reports that mentioned invasive slider turtle populations, across 23 prefectures, 16 of which were amongst the 66 prefectures comprising the middle and lower Yangtze river basin; 14 news reports were amongst mainland China's other 272 prefectures (Fig. 1). Similarly, 74 news reports mentioning snapping turtles involved 42 prefectures in the Yangtze region, whereas only 26 reports were from elsewhere in China (Fig. 1). This indicates significantly more reports of invasive turtles in the Yangtze region ( $\chi^{2}$ with Yates's correction, $\mathrm{P}<0.05, \mathrm{df}=1$, for both taxa). Reports mentioned 'ceremonial animal release' events (12 for slider and four for snapping turtles) and reported predation on native species such as fish, tadpoles, small turtles and eggs of waterfowl (nine for slider and three for snapping turtles).

The estimated c. 3,792,00o turtles traded per year on Taobao.com, as extrapolated from our surveys, suggests that e-commerce is contributing to the purchase and release of potentially invasive turtle species in China. This number is greater than the c. 500,000 turtles sold from aquaculture centers in 2002 (Shi et al., 2008). In addition to Taobao.com, other smaller e-commerce platforms (e.g. JD.com, 1688.com) also offer turtles for sale, and thus our findings provide an indication of only a portion of the e-commerce trade of freshwater turtles in China.

Hulme et al. (2008) identified six introduction pathways (release, escape, contaminant, stowaway, corridor and unaided) that can facilitate the establishment of alien vertebrate pest species (Kraus, 2015) such as invasive freshwater turtles. In addition to turtles that escape from aquaculture facilities (Casimiro et al., 2018), Buddhists release various exotic species (including turtles) deliberately, hoping to generate good karma (Liu et al., 2012). Eighty-eight of 123 Buddhist temple release event organizers surveyed in China released large numbers of turtles and other invasive species (e.g. American bullfrog Lithobates catesbeianus, Asian swamp eels Monopterus albus, Oriental weatherfish Misgurnus anguillicaudatus, several Cyprinid species; Liu et al., 2013).

Currently, there are no specific regulations or legislation pertaining to importation, domestic trade and captive breeding of non-native turtles in China. Snapping turtles are promoted as food, as a source of medicines and as pets, under China's Ministry of Agriculture announcement No. 485, 2005. Preventing further introductions and regulating turtle trade is challenging, with options such as eradication, containment and control difficult and expensive to implement (Hulme, 2009). A multi-pronged approach is most feasible, managing risks from trade and tightening regulations, implementing punitive fines, and policing breeding facilities (Shi et al., 2008) and importation (Perrings et al., 2005). Given the massive volume of online trade in 

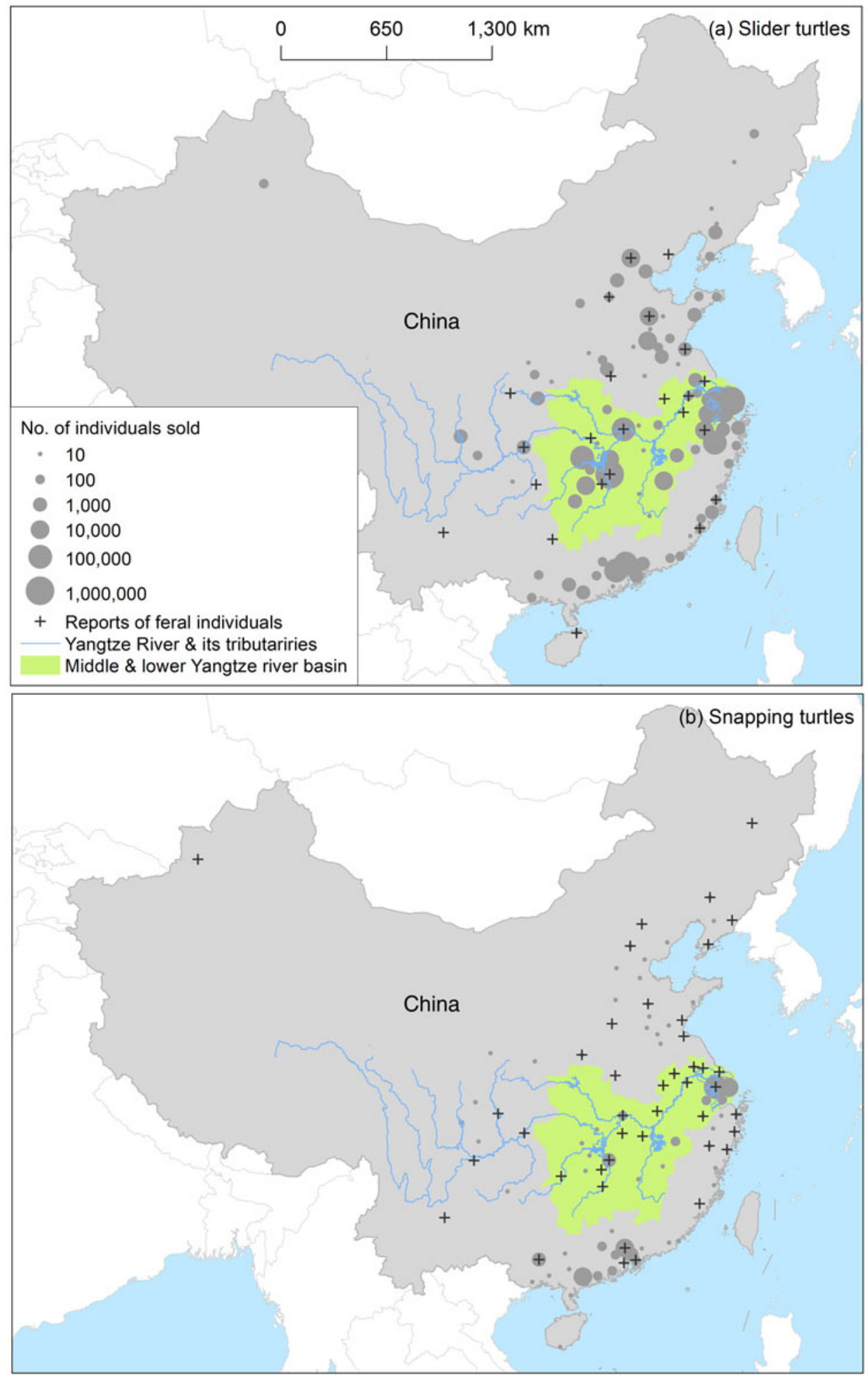

FIG. 1 The prefectures where (a) slider turtles Trachemys scripta elegans and

(b) snapping turtles (Chelydra spp. and Macrochelys spp.) were offered for sale on Taobao.com and where invasive populations were reported during 2008-2018, and the middle and lower Yangtze river basin. invasive species, including animals other than turtles (Lenda et al., 2014), and plants (Humair et al., 2015), and the consequent invasion risk, we recommend that including an ecological hazard warning should be compulsory for all advertisements for taxa known to be invasive. This should be enforced through amendments to advertising laws and/ or through self-regulation codes of conduct implemented across the internet industry. We acknowledge, however, that attempts to regulate turtle breeding and trading could face resistance on both social and economic grounds. 
Acknowledgements We are grateful for the support provided by the China West Normal University (Grant 17BO10).

Author contributions Study design: ZMZ; writing: CN, CDB, DWM, ZMZ; data collection: SL, YZ, KJZ, FL; analysis: SL.

\section{Conflicts of interest None.}

Ethical standards This research abided by the Oryx guidelines on ethical standards. The Taobao.com customers were anonymous and there was no invasion of personal privacy.

\section{References}

Casimiro, A.C.R., Garcia, D., Vidotto-Magnoni, A.P., Britton, J.R., Agostinho, A.A., De Almeida, F.S. et al. (2018) Escapes of non-native fish from flooded aquaculture facilities: the case of Paranapanema River, southern Brazil. Zoologia, 35, e14638.

Chen, X. (2017) Study on biodiversity and geographical distribution of amphibians and reptiles in Bohai Rim Region. MSc thesis. Shenyang Normal University, Shenyang, China.

Chen, X., Lu, Y. \& Li, P. (2017) Prediction of potential geographic distribution for common snapping turtle (Chelydra serpentina) based on MaxEnt modelling. Chinese Journal of Wildlife, 3, 467-472.

Chen, D., Xiong, F., Wang, K. \& Chang, Y. (2009) Status of research on Yangtze fish biology and fisheries. Environmental Biology of Fishes, 85, 337-357.

Ficetola, G.F., Thuiller, W. \& Padoa-Schioppa, E. (2009) From introduction to the establishment of alien species: bioclimatic differences between presence and reproduction localities in the slider turtle. Diversity and Distributions, 15, 108-116.

Hulme, P.E. (2009) Trade, transport and trouble: managing invasive species pathways in an era of globalization. Journal of Applied Ecology, 46, 10-18.

Hulme, P.E., Bacher, S., Kenis, M., Klotz, S., Kühn, I., Minchin, D. et al. (2008) Grasping at the routes of biological invasions: a framework for integrating pathways into policy. Journal of Applied Ecology, 45, 403-414.

Humair, F., Humair, L., Kuhn, F. \& Kueffer, C. (2015) E-commerce trade in invasive plants. Conservation Biology, 29, 1658-1665.

Kobayashi, R., Hasegawa, M. \& Miyashita, T. (2006) Home range and habitat use of the exotic turtle Chelydra serpentina in the Inbanuma Basin, Chiba Prefecture, Central Japan. Current Herpetology, 25, 47-55.
KRAUS, F. (2015) Impacts from invasive reptiles and amphibians. Annual Review of Ecology, Evolution, and Systematics, 46, 75-97.

Lenda, M., Skórka, P., Knops, J.M., Moroń, D., Sutherland, W.J., Kuszewska, K. et al. (2014) Effect of the internet commerce on dispersal modes of invasive alien species. PLOS ONE, 9, e99786.

LiN, Y., GAO, Z. \& ZHAN, A. (2015) Introduction and use of non-native species for aquaculture in China: status, risks and management solutions. Reviews in Aquaculture, 7, 28-58.

Liu, X., McGarrity, M.E., Bai, C., Ke, Z., \& Li, Y. (2013) Ecological knowledge reduces religious release of invasive species. Ecosphere, $4,1-12$.

Liu, X., Mcgarrity, M.E. \& Li, Y. (2012) The influence of traditional Buddhist wildlife release on biological invasions. Conservation Letters, 5, 107-114.

Macdonald, D.W., King, C.M. \& Strachan, R. (2007) Introduced species and the line between biodiversity conservation and naturalistic eugenics. In Key Topics in Conservation Biology, Volume 1 (eds D.W. Macdonald \& K. Service), pp. 173-185. Blackwell Publishing, Oxford, UK.

Moran, P.A. (1950) Notes on continuous stochastic phenomena. Biometrika, 37, 17-23.

Pejchar, L. \& Mooney, H.A. (2009) Invasive species, ecosystem services and human well-being. Trends in Ecology and Evolution, 24, 497-504.

Pelicice, F.M., Vitule, J.R.S., Lima Junior, D.P., Orsi, M.L. \& Agostinho, A.A. (2014) A serious new threat to Brazilian freshwater ecosystems: the naturalization of nonnative fish by decree. Conservation Letters, 7, 55-60.

Perrings, C., Dehnen-Schmutz, K., Touza, J. \& Williamson, M. (2005) How to manage biological invasions under globalization. Trends in Ecology and Evolution, 20, 212-215.

Rangel, T.F., Diniz-Filho, J.A.F. \& Bini, L.M. (2010) SAM: a comprehensive application for spatial analysis in macroecology. Ecography, 33, 46-50.

Sharpe, D.M.T., De León, L.F., González, R. \& Torchin, M.E. (2017) Tropical fish community does not recover 45 years after predator introduction. Ecology, 98, 412-424.

Shi, H.T., Parham, J.F., Fan, Z.Y., Hong, M.L. \& Yin, F. (2008) Evidence for the massive scale of turtle farming in China. Oryx, 42, 147-150.

XIAO, X. (2015) Maximum entropy niche-based modeling of potential geographical distributions of Lithobates catesbeianus and Trachemys scripta in China. MSc thesis. Kunming Institute of Zoology, Chinese Academy of Sciences, Kunming, China. 